UDK $577.1: 61$

ISSN 1452-8258

J Med Biochem 37: 279-288, 2018

Review paper

Revijski rad

\title{
UNCERTAINTY OF MEASUREMENT IN LABORATORY MEDICINE
}

\section{MERNA NESIGURNOST U LABORATORIJSKOJ MEDICINI}

\author{
Neda Milinković1,2, Svetlana Ignjatović ${ }^{1,2}$, Zorica Šumarac ${ }^{1}$, Nada Majkić-Singh $^{3}$ \\ ${ }^{1}$ Center for Medical Biochemistry, Clinical Center of Serbia, Belgrade, Serbia \\ ${ }^{2}$ Department for Medical Biochemistry, University of Belgrade, School of Pharmacy, Belgrade, Serbia \\ ${ }^{3}$ Society of Medical Biochemists of Serbia, Belgrade, Serbia
}

\begin{abstract}
Summary
An adequate assessment of the measurement uncertainty in a laboratory medicine is one of the most important factors for a reliable interpretation of the results. A large number of standards and guidelines indicate the need for a proper assessment of the uncertainty of measurement results in routine laboratory practice. The available documents generally recommend participation in the proficiency schemes/ external quality control, as well as the internal quality control, in order to primarily verify the quality performance of the method. Although all documents meet the requirements of the International Standard, ISO 15189, the standard itself does not clearly define the method by which the measurement results need to be assessed and there is no harmonization in practice regarding to this. Also, the uncertainty of measurement results is the data relating to the measured result itself, but all factors that influence the interpretation of the measured value, which is ultimately used for diagnosis and monitoring of the patient's treatment, should be taken into account. So in laboratory medicine, an appropriate assessment of the uncertainty of the measurement results should have the ultimate goal of reducing diagnostic uncertainty. However, good professional laboratory practice and understanding analytical aspects of the test for each individual laboratory is necessary to adequately define the uncertainty of measurement results for specific laboratory tests, which helps to implement good clinical practice. Also, setting diagnoses in medicine is a decision with a certain degree of uncertainty, rather than statistically and mathematically calculated conclusion.
\end{abstract}

Keywords: ISO 15189, laboratory medicine, measurement uncertainty

Address for correspondence:

Neda Milinković

Center for Medical Biochemistry, Clinical Center of Serbia,

Višegradska 26, 11000 Belgrade, Serbia

Fax phone number: +381113615631

e-mail: nedanvkvc@gmail.com

\begin{abstract}
Kratak sadržaj
Adekvatna procena nesigurnosti rezultata merenja u biohemijskoj laboratoriji je jedan od najznačajnijih faktora za pouzdanu interpretaciju rezultata. Veliki broj standarda i vodiča ukazuju na neophodnost pravilne procene nesigurnosti rezultata merenja u rutinskoj laboratorijskoj praksi. Dostupni dokumenti uglavnom preporučuju učešće u šemama osposobljenosti/spoljašnjoj kontroli kvaliteta, kao i svakodnevno merenje unutrašnjih kontrola kvaliteta, kako bi se primarno proverilo izvođenje metode. Mada svi dokumenti zadovoljavaju zahteve internacionalnog standarda ISO 15189, sam standard ne definiše jasno metodu kojom treba procenjivati nesigurnost rezultata merenja i ne postoji harmonizacija u praksi. Takođe, nesigurnost rezultata merenja je podatak koji se odnosi na sam izmereni rezultat, ali treba uzeti u obzir sve faktore koji utiču i na interpretaciju izmerene vrednosti, koja se u krajnjem koristi za dijagnozu i praćenje lečenja pacijenta. Tako da u laboratorijskoj medicini odgovarajuća procena nesigurnosti rezultata merenja treba da ima za krajnji cilj smanjenje dijagnostičke nesigurnosti. Ipak, dobra profesionalna laboratorijska praksa i razumevanje analitičkih aspekata testa za svaku pojedinačnu laboratoriju je neophodno da bi se adekvatno definisala procena nesigurnosti rezultata merenja za specifična laboratorijska ispitivanja, čime se pomaže sprovođenje dobre kliničke prakse. Takođe, postavljanje dijagnoze u medicini je donošenje odluke sa određenim stepenom nesigurnosti, pre nego statistički i matematički proračunat zaključak.
\end{abstract}

Ključne reči: ISO 15189, laboratorijska medicina, nesigurnost merenja 


\section{Evolution of the concept of measurement uncertainty}

Measurement uncertainty is a metrological concept that is used to objectively evaluate the quality of measurement results. The idea of measurement uncertainty dates back to the 16th century, when scientists from various applied sciences (astronomy, geodesy, experimental physiology, genetics and sociology) wanted to show the quality of the results of their measurements. They mostly changed the measurement conditions and monitored the influence of various factors leading to the final measurement result, which led to the development of the concept of mathematical modeling of these factors in order to assess the measurement uncertainty of the results $(M U)(1-3)$.

The introduction of the concept of $M U$ in routine laboratory practice began only in the 80 s of the last century (4). Due to the lack of consensus in the international scientific community on expressing the uncertainty of measurement, the International Bureau for Weights and Measures (Bureau International des Poids et Mesures, BIPM) established a working group aimed at writing recommendations on expressing measurement uncertainty (4). The document »Recommendation INC-1 - Expression of Experimental Uncertainty« was approved by the International Committee for Weights and Measures (Comité International des Poids et Mesures, CIPM) (5). CIPM suggests that the International Organization for Standardization (ISO) develops a master document for measurement uncertainty based on the recommendations of the BIPM working group. The ISO Technical Advisory Group for Metrology (TAG 4) was responsible for writing a guide, with seven organizations from various fields participating: BIPM, International Electrotechnical Commission (IEC), ISO, International Organization of Legal Metrology, OIML), the International Union of Pure and Applied Chemistry (IUPAC), the International Union of Pure and Applied Physics (IUPAP) and the International Federation of Clinical Chemistry and Laboratory Medicine (IFCC), a representative for medical laboratories. TAG 4 defined Workgroup 3 (ISO/TAG 4/WG 3) with a panel of experts from BIPM, OIML, IEC and ISO. The Guide to the Expression of Uncertainty in Measurement (GUM) was first published in 1993, and two years later corrected and re-printed. Since 2008, when BIPM republished the corrected edition of the original document, the GUM can be downloaded free of charge from the BIPM website (6).

It is important to note that the terminology used in the GUM document on the assessment of measurement uncertainty was taken from the International Vocabulary of Metrology (VIM), which is also available on the BIPM website (7). However, the interpretation of this dictionary is, until now, the main problem in the proper application and assessment of $M U$ in routine laboratory diagnostics.
According to the VIM document, $M U$ is "not a negative parameter that characterizes the dissipation of quantitative values attributable to the measured component, based on the information used " (section 2.26) (7). In laboratory medicine, it is accepted that the MU parameter is associated with the result of measurement, which is characterized by the dissipation of a value that could reasonably be attributed to the measured component, i.e. the analyte to be determined (6). MU is the data that ensures the reliability of the result itself. Reliability of the results is necessary in situations where clinically significant decisions are made and represent a quantitative suspicion to the final outcome.

The most frequently numerically represented $M U$ is the measured value \pm extended uncertainty, $U$. Extended uncertainty is the interval in which the result is expected, with a certain degree of confidence (Confidence interval, $\mathrm{Cl}$ ). This is the product of the standard combined uncertainty of $u\left(u_{c}\right)$ and the coverage factor $k$. The choice of the numerical value of the coverage factor depends on the desired reliability with which the MU should be presented. For $\mathrm{Cl}$ approximately $95 \%$, a coverage factor of 2 corresponds, and for a $\mathrm{Cl}$ greater than $99 \%$, $\mathrm{k}$ is usually 3 , where the degrees of freedom for $u_{c}$ are greater than 20.

In clinical chemistry and laboratory medicine, $\mathrm{MU}$ assessment is required as a mandatory/optional item in accordance with ISO 17025 (General Requirements for the Competence of Laboratory for Testing and Calibration) and ISO 15189 (Special Requirements for the Quality and Competence of Medical Laboratories), original and supplementary editions $(2,3)$. The first edition for the ISO 17025 standard was published in 1999, the supplementary edition was published in 2005 (translation of this standard into Serbian - SRPS ISO/IEC 17025:2005). The first edition of the ISO 15189 standard was published in 2003, and the supplementary editions were subsequently published in 2007 and 2012 (the translation of the latest supplemented standard into Serbian - SRPS ISO 15189:2014).

\section{Models for calculating the measurement uncertainty of the results}

The literature data point to two general models that can be used to evaluate the MU: the original bottom-up model based on the recommendations of the GUM document and the phenomenologically topdown model based on quality control data.

\section{Bottom-up model}

The only normative document, which is also considered a "bible of uncertainty", is the GUM document. Theoretical modeling relies on the principles 
of the original document published in 1980 (4). The basic principles explained in this document are as follows:

- The uncertainty of the result of a measurement consists of several components, which can be grouped into two categories according to the way in which their numerical value is estimated:

Components that are assessed by statistical methods (Type A),

Components that are assessed by other means (Type B).

- Classification in these two categories is not always simple, so components are usually defined as random and systemic uncertainties. The concept of systemic uncertainty should be avoided, as it may be misinterpreted. Each detailed uncertainty report should contain a complete list of components and in particular emphasize the method by which the numerical value of the uncertainty for each component are obtained:

- Components belonging to Type A can be represented by estimated variations (or estimated standard deviation, SD) and number of degrees of freedom, $v$. Where appropriate, covariances should also be indicated.

- The components belonging to Type B can be presented as quantitative values (which roughly explain the assumed variations). Quantitative values can be treated as variations and as SD. In the same way, covariances should also be treated.

- Combined uncertainty should be displayed as a numerical value obtained by applying the usual method of combining variations. Combined uncertainty and its components should be expressed as standard deviations.

- If it is necessary to show the overall uncertainty, the combined uncertainty should be multiplied by the factor, which should be clearly indicated, and it is designated as extended uncertainty (4). which:

Specified principles provide a methodology in

- An uncertainty assessment should include a combination of major sources of uncertainty

- Uncertainties for random and systemic error components should be treated as equal

- Uncertainty components are expressed as combined standard uncertainty or extended uncertainty (8).

The approach proposed by the GUM document is based on a model that is designed to understand the interconnection of all sources of uncertainty that significantly affect the result. Significant systemic errors should be corrected and should not be taken into account when calculating uncertainties. All major sources that lead to the spread of uncertainty are combined and the presented uncertainty is the combined uncertainty \pm the quantitatively presented measured value.

This so-called up model (bottom-up model), which the GUM suggests, is in function of various inputs, i.e. factors leading to the final $M U$, i.e. has a very large budget of uncertainty (a list of factors leading to MU) (9). It is necessary to define a large number of variations and covariances and use complex mathematical modeling, so it is not suitable for use in routine laboratory medicine. Also, the effort and cost of assessing the uncertainty of the measurement results should be proportional to the required clinical quality of measurement (10).

The GUM document presents general rules for assessing and expressing uncertainties in measurement, rather than detailed technological-specific instructions (6). Although the principles of this document are applicable to measurements in biology and chemistry, they were initially valid for measurements in mathematics and physics. The document does not explain how an evaluated $M U$ can be used to match the result obtained with other similar results, how to determine the limit of tolerance in the work process and assess what corrective actions should be taken.

Because of all the previously mentioned, the GUM document indicates that specific standards based on the GUM document (6) should be developed for each specific area. These standards should be a simplified version of the original GUM document, but contain details that correspond to the level of accuracy and complexity of the corresponding measurement.

\section{Top-down model}

Laboratory diagnostics is a medical discipline that plays an important role in diagnosis, risk assessment, treatment and monitoring of the patient. Therefore, in laboratory medicine, precise and accurate routine measurements are needed, which ensure the reliability of the measurement result itself, and thus adequate management of the patient. There are a large number of different pre-analytical, analytical and post-analytical factors that influence MU in routine laboratory diagnostics, so the practical application of the GUM model is not possible.

In 2000, Eurachem/CITAC published the Quantifying Uncertainty in Analytical Measurement (QUAM) paper, and in 2012, a supplement for a unique application for assessing measurement 
uncertainty in chemistry (11). This document examines the practical experience in assessing the uncertainty of measurement in chemical laboratories, and emphasizes the need to integrate procedures that assess the uncertainty of measurement with measurements of existing quality control carried out in laboratories. In this way, the validation of the method in the MU assessment was clearly enabled, and in full compliance with the GUM document, which enabled the empirical approach or the top-down model of the MU assessment in the routine medical laboratories (9).

The top-down model meets the need of chemical laboratories, but it is often of little use for methods used in medical laboratories. Nevertheless, the concept of a top-down model is in accordance with ISO 17025 and ISO 15189 standards, so the QUAM document is the appropriate reference for supporting $M U$ assessment in a routine medical laboratory (11).

Nordic countries Technical report, NordTest TR 537 and ISO 11352 standard, which explains the assessment of measurement uncertainty based on validation and quality control data (ISO 11352 Water Quality Estimation of Measurement Uncertainty Based on Validation and Quality Control Data) explain the phenomenological approach of the top-down model in the $M U$ assessment $(12,13)$.

In routine medical laboratories, the application of a top-down model is possible provided all factors of impact are known and covered, but also representative for all measurements by the same method. Two major impacts on measurement uncertainty in routine medical laboratories are random and systemic effects (14). These two types of effects can be presented within the intra-laboratory precision and the residual bias of measurement, and are part of the analytical error in the medical laboratory. A random error is a measurement component that varies in an unpredictable manner, while the systemic error remains constant, but the change can be predicted (14).

A top-down approach is practical for routine use, but it can override a systemic error of determination. Although this is considered to have no significant impact on the accuracy of the method, since commercial methods of determination with the same bias are used, in general. However, correction of the systemic error is often necessary - not only when using different methods, but also for estimating the variation in the value of the blank test, the impact of interference or incomplete recovery (15).

In this sense, it is necessary to display the following steps for the top-down model:

- Clearly define which analyte is measured, in which matrix, and by what method,
- Quantify the MU for the control sample (Type A) (reproducibility within the laboratory, Rw) and indicate potential impacts that are not covered by the control sample,

- Quantify the bias for the method in the laboratory,

- Display uncertainty components as standard uncertainty (SD),

- Calculate the combined standard uncertainty ( $u_{c}$, root from the sum of squares of individual standard uncertainties),

- Calculate extended uncertainty $\left(U=2 \times u_{c}\right)$,

- Show extended uncertainty as \pm _\%.

If the control sample is unstable, reproducibility can be achieved by analyzing the duplicate measurement in a patient sample (12). The results of the duplicate are analyzed and represented on the $\mathrm{R}$ map (map for the range), to which the data of the difference of two measurements are entered directly. This map can also be presented in the form of \% of the mean value for the analyzed pair of measurements in one sample. This approach is useful when concentrations of the analyte vary in a lot of controls that often change.

\section{Total error concept}

The concept of total error calculation (Total Error, TE) was introduced in 1974, with the aim of quantitative approach in assessing the acceptability of the measurement procedure (16). TE represents the expression of the overall deviation of the test result from its exact value and is initially shown by the following formula: $\mathrm{TE}=$ bias $+\mathrm{z} \times \mathrm{CV}$. The estimation of the TE takes into account both random and systemic errors: it means knowledge of the bias and the analytical coefficient of variation $(\mathrm{CVa})$. Bias is calculated using the following formula:

$$
\operatorname{Bias}(\%)=\left(x-y_{0}\right) / y_{0} \times 100
$$

where $x$ is the obtained value, and $y_{0}$ is the target value. CVa represents the percentage of the standard deviation of the mean value of the result $(S D / x \times 100)$. However, data for imprecision can be used instead of CV data. The statistical $z$ value is a table number describing the level of reliability of the result (which is usually about 95\%) for a measurable error, despite the remaining $5 \%$ chance that the test result may exceed this limit.

A preferred total allowable analytical error (TEa) in routine laboratory medicine can be calculated from the following formulas:

$$
\begin{aligned}
& \mathrm{TEa}=\text { Bias }+1.65 \times \text { imprecision } \\
& \mathrm{TEa}=\text { Bias }+1.65 \times \mathrm{SD}
\end{aligned}
$$


If the value is $Z=1.65$, one-sided data distribution with a $\mathrm{Cl}$ of $95 \%$ is observed. For most situations in routine work, the following formula applies: $\mathrm{CVi}$

$$
\mathrm{TEa}<0.25 \times\left[\mathrm{CVi}^{2}+\mathrm{CVg}^{2}\right]^{1 / 2}+\mathrm{z} \times 0.5 \times
$$

where $\mathrm{CVi}$ is a variation within a person (intraindividual variation), and $\mathrm{CVg}$ variations between individuals (inter-individual variation) (17).

A critical error (Critical Error, CE) can also be calculated based on the following formula (18):

$$
\Delta \mathrm{CE}=[(\mathrm{TE} a-\mathrm{Bias}) / \mathrm{SD}]-1.65
$$

The value of CE, i.e. changes of the TEa can be used in the assessment of results and the selection of appropriate quality control (QC or EQA).

The TE concept requires that the exact value of the result should be known, because the error is inherent in the measurement, otherwise TE cannot be calculated (19). On the contrary, in the concept of uncertainty of measurement, it is assumed that the exact value of the result cannot be known. Unlike the TE concept, when estimating the MU method, the lack of accurate value of the results is underlined, with the assertion that there is a lack of accurate knowledge of the true value of the result (14).

Literature data indicate that the imprecision of the method as an indicator of random error of determination is the main component of MU (20). Also, if bias as an indicator of systemic error is not negligible, i.e. clinically significant, can be removed by correcting the analyte or recalibration. When bias cannot be removed or treated as any other source of uncertainty, it should be included in the calculation of MU. If this is not possible, a medical laboratory may display QC data and apply the TE concept to the MU assessment (14).

\section{Objectives in achieving measurement uncertainty of the results}

In routine medical laboratories, it is important to set up and achieve appropriate goals for MU. This means that the uncertainty of measurement is to give the result and procedure within the clinically acceptable limits, so that the results are of the appropriate quality and reliability for patient management. Depending on the physiology of the analyte, the type of sample and the clinical use of the determined results, the goals can be based on the biological variation or the recommendations and the professional opinions of the experts. There are limitations in meeting targets in relation to the measurement characteristics of the procedures and the instruments on which the analyte is measured, which should be taken into account in the MU assessment.
In order to achieve the objectives of $M U$ it is necessary to achieve traceability. According to the VIM document, traceability is "Characteristic of measurement results so that the result can be linked to references through a documented continuous calibration chain, each contributing to measurement uncertainty« (7). Measurement uncertainty and bias are determined according to the metrological chain of traceability (9). Accuracy, laboratory accreditation levels, and instability and material costs increase significantly from medical laboratories to the top of the hierarchy, from routine medical laboratories to the International System of Units (SI). On the contrary, the measurement uncertainty of bias, and the availability of materials are reduced from the bottom to the top. Due to the inaccessibility of reference materials and methods, this traceability chain has not been properly implemented in medical laboratories (21). Medical traceability is difficult to achieve due to the physico-chemical complexity of the samples in which the analyte is determined, which mainly results from intra- and inter-individual biological variations (22).

\section{Biological variability of the analyte}

The biological variability of the analyte examined in the samples of patients in laboratory medicine may be related to:

- Variations during the course of life, resulting from physiological changes, growth, aging, pregnancy, menopause, or some other normal circumstances,

- Predictable cyclical variations, which can be daily, monthly or seasonal,

- Random variations, which depend on the individual homeostatic mechanisms of each individual (20).

Sources of random variation that affect the result of the analyte measured in the patient sample are:

- Pre-analytical, which involve preparing a patient, collecting and handling the sample,

- Analytical, which imply imprecision and bias,

- Biological, which are the most important, and involve variation within the person.

In order to achieve the results of an appropriate quality, all sources of variation need to be minimized by properly assessing the biological variation components (within and between individuals). In everyday laboratory work, the result of the required parameter for a diagnostic purpose is usually compared to the population reference interval or with the limit value for the parameter itself. Therefore, it is necessary for laboratories to maintain an appropriate, centered 
distribution of results and minimize analytical bias. In the case of monitoring the results, when the successive results of the same analyte are examined, it is necessary to minimize analytical imprecision as the main source of variation in the laboratory (23).

In order to achieve the appropriate analytical characteristics of the methods in routine laboratory diagnostics, it is necessary to define and analyze the desirable characteristics for imprecision and bias, which presents random and systemic effects that have an impact on MU.

Literary data defines three levels of analytical goal for imprecision and analytical bias (17, 23-25).

- Imprecision

Optimal: $\mathrm{CVa} \leq 0.25 \times \mathrm{CVi}$ (increases the variability of the result by $3 \%$ )

Preferred: $\mathrm{CVa} \leq 0.50 \times \mathrm{CVi}$ (increases the variability of the result by $12 \%$ )

Minimum: $\mathrm{CVa} \leq 0.75 \times \mathrm{CVi}$ (increases the variability of the result by $25 \%$ )

- Bias

Optimal: Bias $\leq 0.125\left(\mathrm{CVi}^{2}+\mathrm{CVg}^{2}\right)^{1 / 2}$ (increases the score outside the reference range by $3.3 \%$ )

Preferred: Bias $\leq 0.250\left(\mathrm{CVi}^{2}+\mathrm{CVg}^{2}\right)^{1 / 2}$ (increases the score outside the reference range by $4.4 \%)$

Minimum: Bias $\leq 0.375\left(\mathrm{CVi}^{2}+\mathrm{CVg}^{2}\right)^{1 / 2}$ (increases the score outside the reference range by $5.7 \%$ )

In order to evaluate the characteristics of analytical procedures in the laboratory, in addition to calculating imprecision and bias, biological variability data can be used to calculate the sigma metric, which can predict for which tests it will be necessary to implement a minimum quality control (26). The following formula is used to calculate the sigma metric:

$$
\rho=(\% \mathrm{TEa}-\% \text { Bias }) / \% \mathrm{CVa}
$$

Biological variability data can be used in the assessment of a clinically significant change in two consecutive results for the same analytic for the same patient, by calculating the Reference Change Value, RCV (27).

$$
\mathrm{RCV}=2^{1 / 2} \times \mathrm{Z} \times\left[\mathrm{CVa}^{2}+\mathrm{CVi}^{2}\right]^{1 / 2}
$$

The practical benefit of conventional population reference values can be estimated by analyzing biological variability data, i.e. by calculating the index of individuality (II) for each analyte (23).

$$
\begin{aligned}
& I I=\left(\mathrm{CVa}^{2}+\mathrm{CVi}^{2}\right)^{1 / 2} / \mathrm{CVg} \\
& \approx \mathrm{CVi} / \mathrm{CVg}(\text { if } \mathrm{CVa} \leq \mathrm{CVi})
\end{aligned}
$$

The practical benefit of the reference values will be greater for analytes that have low II (>1.4), compared to those having large II $(<0.6)(28)$.

Knowing the data for RCV and II is of great importance for clinical classifications (diagnosis, prognosis or monitoring of the patient). To monitor the patient's condition, it is desirable that the analyte has a lower RCV, which indicates a high sensitivity of the test, and for the diagnosis it is desirable that the analyte has a high II (23).

Also, biological variability data of the analyte can also be used to determine the optimum sample for analyzing a specific analyte, selecting the appropriate units and samples for displaying analytical results, validating and verifying the method (23).

The most frequently used data for the preferred characteristics for TE, imprecision and bias, calculated on the basis of intra- and inter-individual biological variations, are free available and shown in tabular form, although these values should be updated over a specific time period (29).

\section{Suggested practical models for assessing the uncertainty of measurement results}

The main reasons why a routine medical laboratory should assess the MU are:

- The need or requirement for the laboratory to display the result with the calculated MU values in order to achieve good laboratory practice,

- The need or requirement of a medical laboratory for accreditation (ISO 15189),

- Necessary re-accreditation.

It is also necessary that MU data be made available by manufacturers of in vitro diagnostic devices in order to provide guidance for measurement uncertainty in their information documents (30).

According to Technical Report 1/2007 of the European Federation of National Association for Measuring, Testing and Analytical Laboratories (EUROLAB), four main approaches for evaluation of uncertainty in measurement, which meet the basic principles of uncertainty, are proposed:

- Modeling,

- Validation in a single laboratory (which includes Quality Control, QC),

- Inter-laboratory comparison,

- External quality control data, i.e. laboratory scheme (External Quality Assessment, EQA / Proficiency Testing, PT). 
The laboratory remains on the basis of its own needs, selects and defines one of the mentioned proposal approaches, which will be used in routine work for the assessment of MU.

\section{ISO 15189 standard about measurement uncertainty of result}

Specific requirements for the quality and competence of medical laboratories defined in the international standard ISO 15189 in chapter 5.5, which relates to testing procedures in medical laboratories, in section 5.5.1. explains the selection, validation and verification of test procedures, under point 5.5.1.4 states that the laboratory is obliged to determine the uncertainty of measurement for each phase of the measurement procedure test, which serves to express the quantity of the measured value in the sample of the patient. The laboratory is required to define the requirements for determining the measurement uncertainty for each measurement procedure and regularly re-evaluates the $M U$ (3). This points to the necessity of the dynamics of estimating measurement uncertainty. The laboratory itself estimates the frequency of the $M U$ assessment in relation to the changes that lead to measurement uncertainty.

In addition to general information on $M U$, there are three notes to be considered in routine work:

- Note 1: Components that are relevant to uncertainty are those that relate to the current measurement process, starting with the sample used in the measurement process and ending with the display of the measured value.

- Note 2: Measurement uncertainty can be calculated using the quantitative values obtained by measuring control samples under precisely determined conditions that include the default routine changes for the standard measurement procedure, e.g. change of lot of the reagents or calibrators, different operators, regular maintenance of the instrument.

- Note 3: Examples of the practical benefits of estimating measurement uncertainty are the confirmation that the measured values of patients meet the quality objectives set by the laboratory and can be meaningfully compared with the previous value or with a clinically significant value.

The laboratory shall take into account the measurement uncertainty in the interpretation of the measured result to the users. In cases where the testing process involves measurement steps, but not a measured value report, the laboratory should calculate the uncertainty of each measurement step, if they have an impact in assessing the reliability of the test procedure or have an impact on the displayed results.
ISO 15189:2012 is for the time being the last updated standard, which is also the most important document for defining the characteristics of quality and competence of medical laboratories. This standard is a good guide to routine medical laboratories that need to be accredited, re-accredited, but also to reviewers who work with accreditation bodies (31). However, after a thorough analysis of this document, it is noticed that there is no clearly defined recommendation for a methodology for assessment of the measurement uncertainty. Despite the binding requirements for calculating measurement uncertainty and the elapsed time of 24 years since the GUM has published a guide to expressing measurement uncertainty, practical application has not been successfully adopted in medical laboratories, i.e. there is no harmonization in practice $(32,33)$.

\section{Systematization of measurement uncertainty in medical laboratories}

Since the publication of the GUM document on measurement uncertainty assessment, several different attitudes have been developed in professional scientific circles (34). There are two expert currents that explain the importance of assessing the uncertainty of measuring and/or computing the TE in order to present top quality characteristics and competencies of medical laboratories. However, in routine laboratory work, a practical and easy approach is required, enabling the adoption of appropriate clinical decisions. Complex modular approaches that are explained in literature are usually useful for reagent manufacturers, while simple empirical models are useful for medical laboratories (20). The results of the Global Survey on Measurement Uncertainty, conducted in 2015, indicate the following:

- Most laboratories use, calculate, evaluate and display MU data,

- Most laboratories use a simple formula for assessing MU: they duplicate the imprecision of a method that is monitored over a specific period of time. There is no dominant formula for calculating $M U$ and most of the respondents do not know how to count it,

- A small number of laboratories show the calculated value for $M U$ next to the results of the tests on the report, most labs do not show routine MU data to clinicians,

- The practical benefit of the MU assessment is reflected in the increase in the monitoring of the method, the more frequent contact with the manufacturers of the tests, the change in the frequency of $\mathrm{QC}$ or the recalibration of the method,

- Most laboratories think that clinicians use MU data only once a year and that these data is practically useless, 
- MU data are considered to have an almost negligible impact on the outcome of the patient,

- Some laboratories do not evaluate MU because ISO 15189 is not binding and the regulations of their countries do not require an estimate, i.e. it is up to the laboratory to decide what to do or clinicians do not ask the laboratory about the MU,

- Regulations and requirements for accreditation are the main reasons that the laboratory estimates MU, a very small number of laboratories use this data due to their own practical needs and demands of the clinician (35).

There are a number of guidelines and regulations in the world that explain the importance of MU assessment in medical laboratories and propose different approaches (36-42). Most of these documents suggest a top-down model that implies the use of biological variability data for the calculation of TEa or one of the proposed practical models in routine laboratory diagnostics (QC, EQA, inter-laboratory comparison). For now, the only global guideline and guidance for assessing $\mathrm{MU}$ in medical laboratories is the CLSI C51-A document, which is not free available. This is a newer version of CLSI EP 29-A (20). Nevertheless, literary criticism suggests that most of this document comments on the bottom-up model explained in the GUM document (43). The second part of this guide explains the use of QC data for the MU assessment. However, the Finnish Institute of Environment has provided a free program for calculating MU based on the NordTest TR 537 principles (44).

Assessing the uncertainty of measurement in one of the suggested ways, laboratories should improve and demonstrate the characteristics of the methodology they use to obtain the patient's result. Nevertheless, data of pre-analytical errors, which are significant for the patient's own outcome, are not taken into account in the final assessment of $M U$. Also, ISO is one of the members of the editorial board of GUM and VIM documents, so that the principles to be applied (propagating) rely on uncertainties in measurement, rather than on the concept of TEa (34).

The proposed model that would be easier to understand in routine laboratories implies the calculation of TEa based on the following formula (45):

TEa $=$ bias $+\mathrm{k} \times \mathrm{u}_{\mathrm{c}}$

In addition to bias, the standard combined uncertainty is multiplied by the corresponding factor (extended uncertainty) for the individual outcome, i.e. result (34). Although the calculation does not fully follow the GUM principles, it agrees with the model formula defined in part F.2.4.5 of this document: $U+$ b (6). The complementarity of the measurement uncertainty assessment and calculation of the TEa (46) is directly proposed in addition. However, in practice, laboratories have a much more important standardization in the implementation of good laboratory practice than the monitoring of current discussions on TEs and MUs, which are still not harmonized in practice (47).

\section{Assessment of diagnostic uncertainty}

The ultimate outcome of a complex process in routine medical laboratories is the result of an appropriate quality, i.e. accurate result. $M U$ is a data that relates to the measurement result itself, but it should take into account all the factors that influence the interpretation of the measured value used for diagnosis and monitoring of the patient's treatment. In laboratory medicine, an appropriate MU assessment should have the ultimate goal of reducing diagnostic uncertainty (48). Although the concept of error is more practical for a routine laboratory process, it covers only part of a complex test chain in laboratory medicine. The concept of uncertainty implies the likelihood of the impact of pre-analytical, analytical, biological and postanalytical causes on the outcome of laboratory medicine, which is a clinical response to the outcome. Also, measurement errors are usually a wider set of causes of measurement uncertainty (49). However, accepting the concept of error and the concept of measurement is a prerequisite for achieving appropriate quality characteristics that are the basis of good laboratory practice and contributes to reducing diagnostic uncertainty.

The problem of applying this comprehensive model in routine laboratory medicine is precisely the complex calculation of the MU end-point and the corresponding interpretation, for which knowledge in mathematics and advanced statistics is needed. It is considered that the measurement uncertainty assessment should have a predictive value. Instead of frequentist statistics and determining the frequency of a certain value with previously defined statistical significance, it is necessary to consider all the previous factors, i.e. influences on measurement uncertainty and on the basis of them are predicted by some possible factors that were not taken into account by the original assessment (48). Knowledge of biological, pre-analytical and post-analytical variation, as well as analytical variation is necessary, so that proper use of the concept of uncertainty can contribute to the clinical benefit of measuring methods. Despite the requirements for measurement uncertainty, baseline data are used to determine the analytical error, the question arises as to whether laboratories can combine the concept of measurement uncertainty and the overall error of determination in their routine work, while respecting the necessary dynamics of the MU assessment? 
Methods for calculating MU are not detailed in the standards, accreditation bodies have accepted the concept of error and measurement uncertainty. It is on the laboratory that it defines which approach to use in assessing and displaying the characteristics of the quality of its routine work. Current approaches to measurement uncertainty that use imprecision and accuracy calculation using control samples and use of EQA/PT data relate to the uncertainty of the result of the control sample itself, i.e. uncertainty of the method. In order to evaluate the MU of the patient result it is necessary to use patient samples. In this way, it could affect diagnostic uncertainty which is the ultimate goal of laboratory medicine. The question arises as to whether this is practically possible?

\section{Conclusion}

In scientific circles, there is still no final conclusion on the methodology for evaluation the uncertainty in the measurement in laboratory medicine.

\section{References}

1. Stigler SM. The history of statistics. The measurement of uncertainty before 1900. Published March 1st 1990 by Belknap Press (first published September 26th 1986).

2. General requirements for the competence of testing and calibrating laboratories, ISO/IEC 17025:2005, International Organization for Standardization (ISO)/International Electrotechnical Comission (IEC), 2005

3. Medical Laboratories-Particular requirements for quality and competence, ISO 15189:2012, International Organization for Standardization (ISO), 2012.

4. Bureau International des Poids et Mesures. Rapport BIPM-80/3, Report on the BIPM Inquiry on Error Statements. Sèvres: BIPM; 1980. Retrieved from: http:// www.BIPM.org/utils/common/pdf/rapportBIPM/1980/ 03.pdf. Accessed: January 4, 2016.

5. Giacomo P. News from the BIPM. Metrologia 1982; 18: 43-4.

6. Bureau International des Poids et Mesures. Evaluation of Measurement Data-Guide to the Expression of Uncertainty in Measurement. JCGM 100:2008, GUM 1995 with Minor Corrections. Sèvres: BIPM; 2008. Retrieved from: http://www.BIPM.org/utils/ common/documents/ jcgm/JCGM_100_2008_E.pdf. Accessed: January 4, 2016.

7. Bureau International des Poids et Mesures. JCGM 200:2012 International Vocabulary of Metrology_Basic and General Concepts and Associated Terms, 2008 Version with Minor Corrections. 3rd ed. Sèvres: BIPM; 2012. Retrieved from: http://www.BIPM.org/ utils/common/documents/jcgm/JCGM_200_2012.pdf. Accessed: January 4, 2016.

8. European Federation of National Associations of Measurement, Testing and Analytical Laboratories. Technical
Currently, ISO is implementing a new project on a practical guideline for assessing measurement uncertainty in medical laboratories (ISO/NP TS 20914 Medical Laboratories - Practical Guide for the measurement of measurement uncertainty). Medical laboratories remain to continue to implement the basic principles of good laboratory practice, thus helping each other to implement good clinical practice. Also, setting diagnoses in medicine is a decision with a certain degree of uncertainty, rather than statistically and mathematically calculated conclusion.

Acknowledgments: This study was conducted as a part of the project No 175036 financially supported by the Ministry of Education, Science and Technological Development of the Republic of Serbia.

\section{Conflict of interest statement}

The authors stated that they have no conflicts of interest regarding the publication of this article.

Report No. 1/2007 Measurement uncertainty revisited: Alternative approaches to uncertainty evaluation. EuroLab; 2007. Retrieved from: http://www.eurolab.org/ documents/1-2007.pdf. Accessed: January 4, 2016

9. Pereira P. Uncertainty of Measurement in Medical Laboratories, New Trends and Developments in Metrology, Dr. Luigi Cocco (Ed.), InTech, 2016. DOI: 10.5772/62437. Available from:https://www.intechopen.com/books/ new-trends-and-developments-in-metrology/uncertaintyof-measurement-in-medical-laboratories

10. White $\mathrm{GH}$. Basics of estimating measurement uncertainty. Clin Biochem Rev 2008; 29: 53-60.

11. Ellison SLR, Williams A. Quantifying uncertainty in analytical measurement. 3rd ed. Eurachem/CITAC; 2012. Retrieved from: https://www.eurachem.org/images/ stories/ Guides/pdf/QUAM2012_P1.pdf. Accessed: January 4, 2016.

12. Magnusson B, Näykk T, Hovind H, Krysell M. NordTest NT TR 537 Handbook for calculation of measurement uncertainty in environmental laboratories. 31st ed. Oslo Nordic Innovation; 2011. Retrieved from: http://www. nordtest.info/index.php/ echnical-reports/item/handbook-for-calculation-of-measurement-uncertainty-inenvironmental laboratories-nt-tr-537-edition-3.html. Accessed: January 4, 2016.

13. International Organization for Standardization. ISO 11352 Water Quality-Estimation of measurement uncertainty based on validation and quality control data. Geneva: ISO; 2012.

14. Oosterhuis WP, Bayat $H$, Armbruster D, Coskun A, Freeman KP, Kallner A, Koch D, et al. The use of error and uncertainty methods in the medical laboratory. Clin Chem Lab Med 2018; 56: 209-19. 
15. Theodorsson E, Magnusson B, Leito I. Bias in clinical chemistry. Bioanalysis 2014; 6: 2855-75.

16. Westgard JO, Carey RN, Wold S. Criteria for judging precision and accuracy in method development and evaluation. Clin Chem 1974; 20: 825-33.

17. White $\mathrm{GH}$, Farrance I. Uncertainty of measurement in quantitative medical testing. A laboratory implementation guide. Clin Biochem Rev 2004; 25: Suppl S: 1-24.

18. CLSI C24A3. Statistical quality control for quantitative measurement procedures: principles and definitions. Clinical and Laboratory Standards Institute, Wayne, PA, 2006.

19. Padoan A, Antonelli G, Aita A, Sciacovelli L, Plebani M. Issues and challenges in applicability of measurement uncertainty estimation in medical laboratories. J Lab Precis Med 2017; 2: 69-72.

20. Clinical and Laboratory Standards Institute (CLSI). Expression of measurement uncertainty in laboratory medicine. Approved guideline. 2012. Available online: https://clsi.org/media/1420/ep29a_sample.pdf

21. Vesper $\mathrm{H}$, Thienpont L. Traceability in laboratory medicine. Clin Chem 2009; 55: 1067-75.

22. Fraser CG. Biological variation: from principles to practice. Washington, DC: AACC Press; 2009.

23. Collinson P. Laboratory medicine is faced with the evolution of medical practice. J Med Biochem 2017; 36: 211-5

24. Fraser CG, Hyltoft Petersen P, Libeer JC, Ricos C. Proposals for setting generally applicable quality goals solely based on biology. Ann Clin Biochem 1997; 34: 8-12.

25. Lippi G, Cadamuro J. Novel opportunities for improving the quality of preanalytical phase. A glimpse to the future? J Med Biochem 2017; 36; 293-30.

26. Litten J. Applying sigma metrics to reduce outliers. Clin Lab Med 2017; 37: 177-86.

27. Fraser CG. Reference change values. Clin Chem Lab Med 2011; 50: 807-12.

28. Petersen PH, Sandberg S, Fraser CG, Goldschmidt H. Influence of index of individuality on false positives in repeated sampling from healthy individuals. Clin Chem Lab Med 2001; 39: 160-5.

29. https://www.westgard.com/biodatabase1.htm

30. Dybkaer R. From total allowable error via metrological traceability to uncertainty of measurement of the unbiased result. Accred Qual Assur 1999; 4: 401-5.

31. Burnett D, Poyser KH, Sherwood RA, Wardell J. A practical guide to ISO 15189 in laboratory medicine. ACB Venture Publications, 2016

32. Pereira P. ISO 15189:2012 Medical laboratoriesRequirements for quality and competence. Available online: https://www.westgard.com/iso-15189-2012 requirements-1.htm
33. Plebani M, Sciacovelli L. ISO 15189 accreditation: navigation between quality management and patient safety. J Med Biochem 2017; 36: 225-30.

34. Pereira P, Seghatchian J. Balance of the unsuccessful systematization of measurement uncertainty in medical laboratories. Transfus Apheresis Sci 2017; 56: 103-4.

35. https://www.westgard.com/mu-global-survey.htm

36. ISO 21748:2017 "Guidance for the use of repeatability, reproducibility and trueness estimates in measurement uncertainty estimation «, International Organization for Standardization (ISO) 2ed, 2017.

37. NIST Technical note 1297 (1994 Edition): "Guidelines for evaluating and expressing the uncertainty of NIST measurement results«.

38. NMKL Procedure No. 5, 2ed 2003: "Estimation and expression of measurement uncertainty in chemical analysis«.

39. UKAS (United Kingdom Accreditation Service) 2000 The expression of uncertainty in testing Edition 1, UKAS Publication ref: LAB 12

40. CAC/GL 54-2004, Guidelines on measurement uncertainty.

41. Technical guide 4, A Guide on measurement uncertainty in medical testing, SAC SINGLAS, 2013.

42. National Pathology Accreditation Advisory Council. Requirements for the estimation of measurement uncertainty. Barton, ACT: NPAAC; 2007.

43. https://www.westgard.com/clsi-c51.htm

44. Virtanen A, Naykki T, Varkonyi E. MUkit - Measurement uncertainty kit. 2012. Available at:http://www.syke.fi/ enUS/Services/Calibration services and contract laboratory/MUkit_Measurement_Uncertainty_Kit. [accessed 22.12.16]

45. Sandberg S, Fraser CG, Horvath AR, Jansen R, Jones G, Oosterhuis W, et al. Defining analytical performance specifications: consensus statement from the 1st Strategic conference of the european federation of clinical chemistry and laboratory medicine. Clin Chem Lab Med 2015; 53: 833-5.

46. Farrance I, Badrick T, Sikaris KA. Uncertainty in measurement and total error -are they so incompatible? Clin Chem Lab Med 2016; 54: 1309-11.

47. Theodorsson E. Quality assurance in clinical chemistry: a touch of statistics and a lot of common sense. J Med Biochem 2016; 35: 103-12.

48. Theodorsson E. Uncertainty of measurement and total error: tools for coping with diagnostic uncertainty. Clin Lab Med 2017; 37: 15-34.

49. Giordani A, Mari L. Error and uncertainty in scientific practice. In Boumans M, Hon G, Petersen A, editors, Pickering \& Chatto, 2014: 79-96. 